\title{
Uso da combinação dos anestésicos tiletamina e zolazepam na imobilização de Ctenomys lami (Rodentia-Ctenomyidae) no sul do Brasil
}

\author{
Use of the anesthetic combination of tiletamine and zolazepam for immobilization \\ of Ctenomys lami (Rodentia-Ctenomyidae) in southern Brazil \\ Gisele Guiomara Stein ${ }^{1}$, J osé Francisco Bonini Stolz ${ }^{2}$, Ingrid Vera Stein ${ }^{1}$, \\ Marina Estrázulas ${ }^{1}$, Vanessa Lipp ${ }^{3}$, Thales Renato Ochotorena Freitas ${ }^{2} \&$ André Silva Caríssimi $^{1}$
}

\begin{abstract}
RESUMO
Estudos sobre contenção química de animais silvestres são de extrema importância para a manipulação destes, minimizando o estresse e garantindo segurança no procedimento anestésico tanto para os animais quanto para a equipe de trabalho. Zoletil ${ }^{\circledR}$ foi utilizado para imobilização de tuco-tucos (Ctenomys lami) capturados no Rio Grande do Sul (Brasil) entre maio e junho de 2008. A dose utilizada foi de $8 \mathrm{mg} / \mathrm{kg}$, por via intramuscular, produzindo um tempo de indução de $2,5 \pm$ 1,05min. A recuperação dos reflexos (quando os animais retornam a decúbito esternal) levou o tempo de 37,3 $\pm 12,32 \mathrm{~min}$ e o

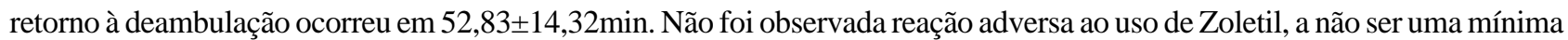
perda na regulação de temperatura. Dois animais vieram a óbito durante a anestesia. Zoletil administrado na dose de $8 \mathrm{mg} / \mathrm{kg}$ foi um efetivo agente para imobilização de tuco-tucos de vida livre.
\end{abstract}

Descritores: anestesia, Ctenomys lami, tiletamina, zolazepam.

\section{ABSTRACT}

Studies about chemical contention are extremely important for wildlife animal's manipulation, to guaranty safety of it and the people who are manipulating them. Zoletil ${ }^{\circledR}$ was used for contention of tuco-tucos (Ctenomys lami) captured in Rio Grande do Sul state (Brazil) between May and June of 2008. The dosage utilized was $8 \mathrm{mg} / \mathrm{kg}$ by intramuscular injection. The induction time was $2,5 \pm 1,05 \mathrm{~min}$. The reflex recuperation (when the animals returned to be on sternal decubitus) took $37,3 \pm 12,32 \mathrm{~min}$ and the ambulation return occurred in 52,83 $\pm 14,32 \mathrm{~min}$. No adverse reaction to Zoletil unless a little temperature regulation loss. Two individuals deceased during anesthesia process. This anesthetic showed to be effective as immobilization agent for tuco-tucos in wildlife.

Keywords: anesthesia, Ctenomys lami, tiletamine, zolazepam. 


\section{INTRODUÇÃO}

A contenção química de animais silvestres visa a possibilitar a manipulação dos indivíduos, de maneira geral, não buscando a anestesia geral, mas sim um estado de imobilidade que permita a realização de um procedimento médico ou manejo mais prolongado, minimizando o estresse do animal e oferecendo segurança para este e para a equipe de trabalho [7].

$\mathrm{O}$ gênero Ctenomys constitui um amplo grupo de 56 espécies de roedores fossoriais [3,9]. A espécie Ctenomys lami está presente em uma região arenosa chamada de Coxilha das Lombas, que se estende do norte do Rio Guaíba em direção a noroeste dos bancos de areia da lagoa dos Barros, cercada por lagoas e banhados no sul do Brasil [2]. A contenção química tem sido realizada frequentemente nesta espécie, porém, não existem trabalhos sobre parâmetros fisiológicos e anestésicos que comprovem a segurança e o bem-estar destes animais durante este procedimento.

Anestésicos dissociativos têm sido amplamente utilizados para contenção de pequenos mamíferos [5]. Um dos anestésicos dissociativos mais comumente usados é a tiletamina. Esta aumenta o tônus simpático central e periférico, resultando em hipertensão e taquicardia. A combinação da tiletamina juntamente com o zolazepan (Zoletil ${ }^{\circledR 1}$ ), um benzodiazepínico, tem sido amplamente utilizada em roedores para pequenos procedimentos cirúrgicos e contenção química [9].
As doses e os efeitos da utilização de Zoletil ${ }^{\circledR}$ em animais do gênero Ctenomys têm sido pouco documentados. $\mathrm{O}$ objetivo do trabalho foi documentar uma dose e os efeitos do Zoletil ${ }^{\circledR}$ na imobilização de tuco-tucos (Ctenomys lami) de vida livre.

\section{MATERIAIS E MÉTODOS}

Este estudo foi conduzido durante os meses de maio e junho de 2008, no Refúgio de Vida Silvestre Banhado dos Pachecos (S 30 05’31,2" W 050 50’35,0"), na cidade de Viamão, Rio Grande do Sul, Brasil. Oito espécimes adultos de Ctenomys lami (6 fêmeas e 2 machos) foram capturados com a ajuda de armadilhas Oneida Victor $\mathrm{n}^{\circ}$ " 0 " colocadas a $20 \mathrm{~cm}$ do interior do túnel e fixadas externamente através de estacas de madeira. Revisões dessas armadilhas foram realizadas de quinze em quinze minutos, para evitar o mal-estar dos animais, em caso de serem capturados. Após a captura, os animais foram colocados dentro de caixas de contenção em local protegido de predadores e aquecimento solar. Decorridos 20 minutos, tempo estimado para que o animal se encontrasse calmo, aferiu-se a frequência respiratória por observação dos movimentos expiratórios e inspiratórios. Logo após, os animais foram pesados e anestesiados. Como anestésico, utilizou-se Zoletil ${ }^{\circledR}$ na dose de $8 \mathrm{mg} / \mathrm{kg}$, por via intramuscular, dose recomendada para Ctenomys torquatus [10]. Após indução, aferiuse a temperatura retal e frequência cardíaca. Também

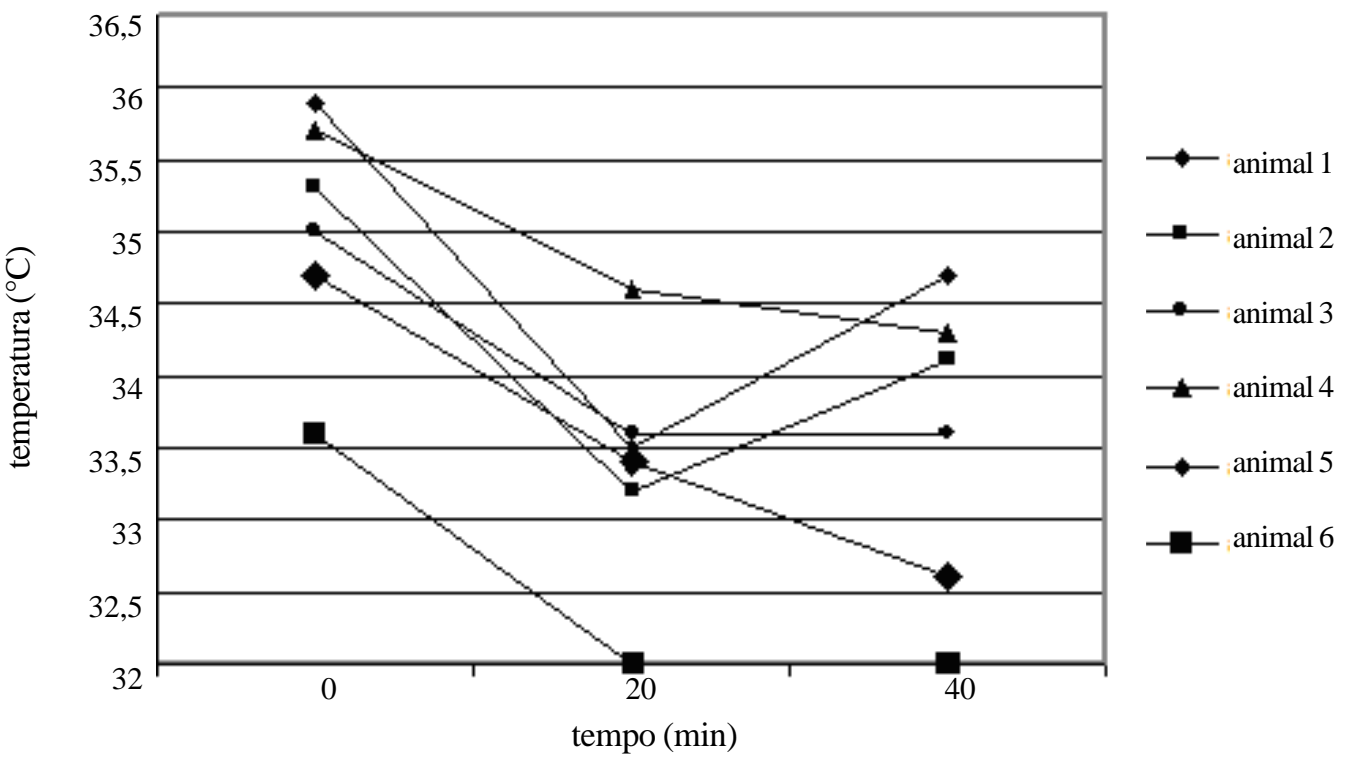

Tempo 0 (zero) $=$ início indução; Temperatura $32^{\circ} \mathrm{C}=$ menor que $32^{\circ} \mathrm{C}$.

Figura 1. Variações na temperatura corporal de tuco-tucos da espécie Ctenomys lami (n=6), durante os tempos 0,20 e 40 minutos na contenção química com $8 \mathrm{mg} / \mathrm{kg}$ de Zoletil ${ }^{\circledR}$ (1:1 combinação de tiletamina e zolazepam) durante os meses de maio e junho de 2008, no Rio Grande do Sul, Brasil. 
Tabela 1. Massa corporal, frequência cardíaca, frequência respiratória, estágios de anestesia e temperaturas retais em diferentes tempos após a anestesia, expressos em média e índice de confiança de 95\%, de Ctenomys lami (n-=6) imobilizados com Zoletil $^{\circledR}$ (1:1 combinação de tiletamina e zolazepam) no Rio Grande do Sul, durante os meses de maio e junho de 2008.

\begin{tabular}{lcc}
\hline Variáveis & Média $(\boldsymbol{\sigma})$ & Variação (IC 95\%) \\
\hline Massa corporal machos $(\mathrm{n}=6)(\mathrm{g})$ & $191,67 \pm 48,9$ & $155-285$ \\
Frequência cardíaca (bat/min) & $207,17 \pm 46,54$ & $139-254$ \\
Frequência respiratória (mov/min) & $66,3 \pm 9,42$ & $48-74$ \\
Estágios de anestesia & & \\
$\quad$ Indução ${ }^{\mathrm{a}}(\min )$ & $2,5 \pm 1,05$ & $1-4$ \\
$\quad$ Recuperação dos reflexos ${ }^{\mathrm{b}}(\mathrm{min})$ & $37,3 \pm 12,32$ & $22-54$ \\
$\quad$ Retorno anestésico ${ }^{\mathrm{c}}(\mathrm{min})$ & $52,83 \pm 14,32$ & $33-68$ \\
Variação da temperatura $\left({ }^{\circ} \mathrm{C}\right)$ retal & & $33,6-35,9$ \\
Temperatura $(\mathrm{t}=0$ min) & $35,03 \pm 0,83$ & $32-34,3$ \\
Temperatura $(\mathrm{t}=20$ min) & $33,33 \pm 0,75$ & $32-34,7$ \\
Temperatura $(\mathrm{t}=40$ min) & $35,55 \pm 1,05$ & \\
\hline
\end{tabular}

andução=tempo da aplicação da droga até decúbito leteral dos animais. ${ }^{b}$ Recuperação dos reflexos=tempo em que $o$ animal retorna à posição de decúbito esternal. ${ }^{\circ}$ Retorno anestésico=tempo decorrido da aplicação da droga até o animal retornar à deambulação.

foram medidos dados biométricos, realizada microchipagem com microchip AnimallTAG ${ }^{\circledR 2}$, e amostras de ectoparasitas e fezes foram coletadas. Coletas sanguíneas também foram realizadas respeitando-se o volume de $10 \%$ peso corporal do animal. Durante a imobilização, a temperatura retal foi aferida com termômetro clínico digital flexível G-Tech ${ }^{\circledR 3} \operatorname{logo}$ após a indução e com intervalos de 20 minutos (Figura 1). A frequência cardíaca foi aferida com auxílio de oxímetro de pulso portátil Moriya ${ }^{\circledR 4}$, sendo o Sensor Universal Y colocado no membro posterior direito, sobre as superfícies laterais da tíbia. Os animais foram monitorados durante toda anestesia até retornarem ao estado normal. Foi medido o tempo (min) de indução (da aplicação até os animais assumirem a posição de decúbito lateral), medido o tempo (min) de recuperação dos reflexos (quando esses se posicionassem em decúbito ventral) e o tempo total (min) em que os animais retornaram às condições de pré-anestesia (momento em que retornaram à deambulação e ao estado de alerta).

As análises estatísticas foram realizadas com o uso do programa BioStat ${ }^{\circledR}$ 2008, versão 5.3.5.1. Foram realizadas estatísticas descritivas, e regressões lineares para avaliar a correspondência entre o peso e o tempo de indução dos animais. Considerou-se significativo $P<0,05$.

\section{RESULTADOS}

A massa corporal, frequência cardíaca, frequência respiratória, estágios de anestesia e temperaturas corporais em diferentes tempos após a anestesia dos espécimes de Ctenomys lami avaliados neste estudo se encontram na Tabela 1. Duas fêmeas vieram a óbito logo após a coleta sanguínea e não foram inseridas nos dados estatísticos. Todos os espécimes foram contidos pela cauda para a aplicação do anestésico por via intramuscular (músculo semitendinoso), apresentando, então, excitação caracterizada por micção, defecação e vocalizações, juntamente com tentativas de fuga e mordedura, variando em intensidade para cada indivíduo. Após aplicação da droga, os animais foram recolocados nas caixas de contenção, onde se observou perda do equilíbrio e movimentos de pedalagem, assumindo a posição de decúbito lateral no final do estágio de indução. Os animais não perderam os reflexos palpebrais durante toda a contenção química, mantendo movimentos involuntários e pobre relaxamento muscular. A média de temperatura retal encontrada no início da indução foi de $35,03 \pm 0,83^{\circ} \mathrm{C}, 20$ minutos após indução foi de $33,33 \pm 0,75^{\circ} \mathrm{C}$, e, aos 40 minutos, a temperatura retal se manteve praticamente constante em comparação à anterior, ficando entre $33,55 \pm 1,05^{\circ} \mathrm{C}$. As correlações encontradas não foram significativas do 
ponto de vista estatístico. Não foram encontradas relações significativas entre o tempo de indução e peso dos animais $(P=0,999)$, nem entre o tempo de recuperação dos reflexos e o peso $(\mathrm{r}=0,281$ e $P=0,590)$. Também não se encontraram relações significativas entre o peso e o retorno à deambulação dos animais $(\mathrm{r}=0,454$ e $P=0,366)$.

\section{DISCUSSÃO}

Foi observado, após análise dos dados constantes da Figura 1, que, para uma melhor determinação nas variações de temperatura, seria necessário o aferimento dessa durante um período mais prolongado, porém, na prática, isso não é possível, pois transcorridos 40 minutos, todos os animais já se apresentavam acordados e agressivos à manipulação.

Algumas desvantagens das anestesias dissociativas é o pobre relaxamento muscular, mantendo os animais, muitas vezes, com reflexos de deglutição e palpebrais [11], sendo prolongado o tempo de recuperação anestésica $[4,6]$. Concordando com a literatura, também foi observado que os roedores da espécie $C$. lami não perderam os reflexos palpebrais durante toda a contenção química, mantendo movimentos involuntários e pobre relaxamento muscular. Devido aos animais não perderem completamente os reflexos, em decorrência do tipo de anestesia utilizada, a dosagem pode servir para contenção e pequenos procedimentos a campo nestes animais, mas não deve ser utilizada para procedimentos invasivos de longa duração. Para esses fins, o Zoletil ${ }^{\circledR}$ não apresentou reações adversas nos animais. O Zoletil ${ }^{\circledR}$ aumenta a margem terapêutica do agente dissociativo, potencializando a indução, o miorrelaxamento e a analgesia sem depressão cardiorrespiratória com baixa incidência de episódios catalépticos [1]. Dois animais vieram a óbito, percebendo-se uma depressão cardiorrespiratória após a coleta sanguínea. Estudos mais detalhados devem ser feitos nesta espécie para uma melhor compreensão das causas dos óbitos.

\section{CONCLUSÕES}

Devido à escassez de dados na literatura sobre parâmetros fisiológicos normais e sob efeito de agentes anestésicos, conclui-se que a dose utilizada de Zoletil ${ }^{\circledR}$ neste trabalho serve como agente para a imobilização de tuco-tucos (Ctenomys lami) de vida livre. Os efeitos encontrados sob a utilização deste fármaco são semelhantes aos encontrados para outros animais domésticos. Porém, a ocorrência de dois óbitos gera a necessidade de estudos mais detalhados sobre doses e efeitos desse agente anestésico nesta espécie animal.

\section{NOTAS INFORMATIVAS}

${ }^{1}$ZZoletil $^{\circledR}$ - Virbac, Carros Cedex, França.

${ }^{2}$ AnimallTAG ${ }^{\circledR}$ - São Paulo, Brasil.

${ }^{3}$ G-Tech ${ }^{\circledR}$ - ACCUMED, Rio de Janeiro, Brasil.

${ }^{4}$ Moriya $^{\circledR}$ - São Paulo, Brasil.

\section{REFERÊNCIAS}

1 Fieni F., Tauinturier D., Denissel E. \& Klethi H. 1988. Uso da associação tiletamina-zolazepan pela via endovenosa na anestesia do cão. Hora Veterinária. 8: 45-8.

2 Freitas T.R.O. 2001. "Tuco-tucos" (Rodentia-Octodontidae) in southern Brazil: Ctenomys lami spec. nov. separated from $C$. minutus Nehring 1887. Studies on Neotropical Fauna and Environment. 36: 1-8.

3 Lacey E.A., Patton J.P. \& Cameron G.N. 2000. Life Underground: The Biology of Subterranean Rodents. Chicago: University of Chicago Press, 449p.

4 Lin H.C. 1996. Dissociative anesthetics. In: Thurman J.C., Tranquilli W.J. \& Benson G.J. (Eds.). Lumb and Jones'veterinary anesthesia. Pennsylvania: Williams and Wilkins, pp.241-296.

5 Massolo A., Sforzi A. \& Lovari S. 2003. Chemical Immobilization of Crested Porcupines with Tiletamine HCl and Zolazepam $\mathrm{HCl}$ (Zoletil) under Field Conditions. Journal of Wildlife Disease. 39: 727-731.

6 Millspaugh J.J., Brundige G.C., Jenks A.J., Tyner C.L. \& Hustead D.R. 1995. Immobilization of rocky mountain elk with Telazolt and xylazine hydrochloride, and antogonism by yohimbine hydrochloride. Journal of Wildlife Diseases. 31: 259262.

7 Pachaly J.R. 1992. Clínica e Manejo de Animais Selvagens. Apostila, Curso de extensão universitária - Setor de Ciências Agrárias, Universidade Federal do Paraná. Curitiba: UFPR, pp.16-22.

8 Pessoa C.A. 2007. Rodentia - Roedores de Companhia (Hamster, Gerbil, Cobaia, Chinchila e Rato). In: Cubas Z.S., Silva J.C.R. \& Catão-Dias J.L. (Eds). Tratado de Animais Selvagens. São Paulo: Roca, pp.443-445. 
Stein G.G., Stolz J.F.B., Stein I.V., Estrázulas M., Lipp V., Freitas T.R.O. \& Carí́ssimi A.S. 2009. Uso da combinação dos anestésicos tiletamina e zolazepam na imobilização de Ctenomyslami...

9 Reig O.A., Bush C., Ortells M.O. \& Contreras J.R. 1990. An overview of evolution, systematics, population and speciation in Ctenomys. In: Nevo E. \& Reig O.A. (Eds). Evolution of Subterranean Mammals at the Organismal and molecular Levels. New York: A.R. Liss Inc., pp.71-96.

10 Silva J., Freitas T.R.O., Marinho J.R., Speit G. \& Erdtmann B. 2000. An Alkaline Single-cell Gel Eletrophoresis (COMET) Assay For Environmental Biomonitoring With Native Rodents. Genetics and Molecular Biology. 23: 241-245.

11 Spinosa H.S., Górniak S.L. \& Bernardi M.M. 2002. Farmacologia aplicada à Medicina Veterinária. Rio de Janeiro: Guanabara, 752p. 